\title{
DISCRIMINACIÓN POR ORIENTACIÓN SEXUAL O IDENTIDAD DE GÉNERO EN CENTROS DE DETENCIÓN DEL ESTADO COLOMBIANO*
}

\author{
Discrimination due to sexual orientation or gender identity \\ in detention centers of the Colombian State
}

Laura Alejandra PEDRAZA PINTO**

"Hablo por mi diferencia, defiendo lo que soy y no soy tan raro. Me apesta la injusticia y sospecho de esta cueca democrática"

Pedro Lemebel

Sumario:

I. Introducción II. Conceptualización de categorías vinculadas a la orientación sexual y la identidad de género III. Violaciones de derechos humanos. IV. Obligaciones del Estado Colombiano V. Recomendaciones. VI. Conclusiones

Resumen: El objetivo del presente artículo es identificar las violaciones a derechos humanos más frecuentes perpetradas contra los reclusos pertenecientes a la comunidad LGBT por parte del personal penitenciario. A su vez, explicar de acuerdo con lo establecido en la legislación nacional e internacional, la responsabilidad del Estado frente a vulneraciones causadas a los detenidos debido a su orientación sexual o identidad de género, la obligación que tienen los centros de detención, como responsables de la ejecución de la pena, de asegurar un trato basado en la dignidad humana con perspectiva en derechos humanos. En consecuencia, se busca proporcionar algunas recomendaciones basadas en los estándares de tratamiento penitenciario.

Palabras clave: Discriminación, orientación sexual, identidad de género, LGBT, reclusos transexuales, centros penitenciarios, libre desarrollo de la personalidad, violaciones de derechos humanos, igualdad, represión de la identidad sexual.

Abstract: The objective of this article is to identify the most frequent human rights violations perpetrated against inmates belonging to the LGBT community by prison staff. At the same time, explain in accordance with the provisions of national and international legislation, the responsibility of the State for violations against detainees due to their sexual orientation or gender identity, the obligation of detention centers as responsible for the execution of the penalty of ensuring a treatment based on human dignity with a human rights perspective. Consequently, the aim is to provide certain recommendations based on prison treatment standards.

\footnotetext{
* La autora agradece las contribuciones que recibió para escribir este artículo, en particular los comentarios realizados por Charles Moyer ex secretario de la Corte Interamericana de Derechos Humanos y Jorge Padilla Coordinador de Educación del Instituto Interamericano de Derechos Humanos.

** Abogada de la Universidad Industrial de Santander y egresada de la Maestría en Justicia Constitucional de la Universidad de Guanajuato.
} 
Keywords: Discrimination, sexual orientation, gender identity, LGBT, transsexual inmates, detention centers, free development of personality, violations of human rights, equality, repression of sexual identity.

\section{Introducción}

En Colombia, históricamente se han suscitado actos prejuiciosos y violentos contra la comunidad LGBT $^{1}$ en razón de su orientación sexual o identidad de género. Muchos de estos vejámenes no solamente se han quedado en la impunidad sino que se han legitimado por la sociedad, generando un sinfín de violaciones de derechos a este grupo que la gran parte de la población somete porque en su imaginario piensan que no deben gozar de respeto e igualdades constitucionales como cualquier habitante del país ${ }^{2}$.

En consecuencia, lideres sociales y organizaciones no gubernamentales han luchado por el reconocimiento y cumplimiento de derechos para esta comunidad. No obstante de que se crean precedentes judiciales para sancionar las transgresiones, usualmente estos no son efectivos ni suficientes. La violencia es sistematizada en todo el país y es aún más preocupante cuando se da en el ámbito penitenciario, dado que allí se materializa diariamente, no sólo por parte de sus compañeros de patio sino también, por los responsables de la ejecución de la pena, encargados de su cuidado y protección, los guardias y personal administrativo.

Los reclusos homosexuales, bisexuales y Trans $^{{ }^{*}}$ forman parte de un grupo particularmente vulnerable en los centros de detención pues son más proclives a sufrir de abusos por parte del personal de la prisión debido a conductas prejuiciosas e ideas discriminatorias que se encuentran en la sociedad y que se acentúan y concretizan en el entorno de estos centros. Estos grupos sufren humillaciones, abusos sexuales, violencia física y psicológica debido a su identidad de género u orientación sexual, por lo que necesitan ciertos cuidados y una protección específica por parte del Estado durante el cumplimiento de su condena.

Teniendo en cuenta que el libre desarrollo de la personalidad y la igualdad ante la ley fueron algunos de los principios que se establecieron en la Carta Política de Colombia de $1991^{4}$, se sostendrá que el Estado colombiano está constitucionalmente obligado a garantizar los mismos derechos y oportunidades a las personas de la comunidad LGBT que se encuentran bajo medida de aseguramiento, sin ejercer ningún tipo de discriminación por razones de sexo. Así, por ejemplo, como sucede con el libre desarrollo de la personalidad que reclama el respeto por las elecciones diversas de vida, o la igualdad y no discriminación que se concibe como una de las prerrogativas de las personas tradicionalmente excluidas y marginadas en la sociedad, se exige al Estado, a las autoridades y a la sociedad, promover las condiciones para que la igualdad sea

\footnotetext{
1 Acrónimo referente a Lesbianas, Gais, Bisexuales, Transexuales, Transgénero y Travestis.

2 Colombia Diversa, Caribe Afirmativo Y Santa María Fundación (2017), Entre el miedo y la resistencia. Informe de Derechos humanos de personas lesbianas, gays, bisexuales y trans en Colombia 2017, Bogotá.

3 Trans $^{*}$ refiere la unificación de las identidades y expresiones, transexuales, transgénero y travestis. En algunas ocasiones se agrega un asterisco al final para ampliar la palabra con el objetivo de incluir a todas las personas con expresiones o identidades de género no conformes.

4 La Constitución Política de Colombia de 1991, también llamada Carta Magna, Carta Política o Carta Fundamental, promulgada el 4 de julio de 1991, a su vez, es ampliamente reconocida como "La Constitución de los derechos humanos". Véase ¿Qué es la Constitución Política?, [en línea], disponible en: http://www.constitucioncolombia. com/historia.php [consultado el 1 de abril de 2019]
} 
real; además de adoptar medidas para salvaguardar a los grupos segregados de actuaciones o prácticas de terceros que mantengan o beneficien situaciones separatistas.

Por lo anterior, considerando las violaciones de derechos humanos identificadas en los centros de detención colombianos y en conexidad con la obligación que tiene el Estado para eliminar y evitar cualquier forma de discriminación, además de ser el encargado por medio de la entidad penitenciaria de proporcionar un adecuado tratamiento penitenciario, se realizarán algunas recomendaciones que se deberían implementar para otorgar el manejo de las necesidades de los reclusos que se encuentran en el supuesto de discriminación por orientación sexual e identidad de género.

\section{Conceptualización de categorías vinculadas a la orientación sexual y la identidad de género}

El reconocimiento de la orientación sexual y la identidad de género son primordiales para la dignidad y la humanidad de todo ser humano. Son conceptos que se están transformando constantemente a partir de la experiencia individual y de la forma en que cada persona asume su sexualidad frente a su desarrollo identitario; de igual forma, hacen parte de la autonomía personal que le permite al individuo decidir sin presiones externas sobre los planes de vida que considere propios, sin transgredir con ello los derechos de los demás.

La orientación sexual se refiere al sentimiento que tiene cada persona de experimentar atracción afectiva, emocional y sexual por personas de un género diferente al suyo (heterosexuales), o de su mismo género (homosexuales), o de ambos géneros (bisexuales); así como la capacidad de mantener relaciones íntimas y sexuales según su decisión 5 .

La identidad de género se refiere a la vivencia personal del género tal como cada individuo la siente interiormente, la cual podría pertenecer o no con el sexo asignado al momento del nacimiento, incluyendo la vivencia individual del cuerpo que podría implicar transformaciones en la apariencia, la imagen y/o la función corporal a través de procedimientos quirúrgicos, terapéuticos o de otra naturaleza, siempre que la misma sea elegida por voluntad propia; así como otras expresiones de género, incluyendo el atuendo y el modo de expresarse ${ }^{6}$. Estas nociones se usan con fines prácticos sin dejar de lado las distintas formas en las que las personas pueden identificarse a sí mismas, sin que por ningún motivo lleguen a ser discriminadas en razón de sus preferencias psicosexuales afectivas ${ }^{7}$.

Por otro lado, es de trascendencia explicar que la discriminación es una práctica que consiste en brindar un trato desfavorable o de desprecio inmerecido a una determinada persona o grupo. Existen personas y grupos que son víctimas de la discriminación todos los días por alguna de sus características físicas, mentales, preferencias sexuales, sus formas de vida que entre otros

5 Léase "Introducción a los principios de Yogyakarta", en Comisión Internacional de Juristas ICJ (2007), Principios de Yogyakarta: Principios sobre la aplicación de la legislación internacional de derechos humanos en relación con la orientación sexual y la identidad de género, pp. 6, [en línea], disponible en: http://www.refworld.org.es/ docid/48244egf 2.html [consultado el 8 de mayo de 2018]

${ }^{6}$ Ídem.

7 Las características con que las personas nacen y los efectos de las experiencias que viven se influencian mutuamente conformando el desarrollo, el cual es un proceso que dura toda la vida. 
aspectos pueden ser motivo de impedimento, rechazo o limitación para el ejercicio de sus derechos $^{8}$.

La discriminación de la comunidad LGBT en centros penitenciarios es una forma de violencia que se naturaliza en tanto no se considera como un hecho denunciable y en tanto que existe poca intervención para prevenir y erradicar las vulneraciones a derechos humanos sufridas por este grupo minoritario. Según el censo del Instituto Nacional Penitenciario y Carcelario (INPEC), establecimiento público adscrito al Ministerio de Justicia y de Derecho de Colombia, responsable de la ejecución de la pena y la atención básica de la población reclusa, señala que:

815 personas LGBTI están recluidas en las cárceles colombianas, de las cuales 350 son mujeres lesbianas, 198 bisexuales, 161 hombres gays, 102 transgeneristas y 4 intersexuales. Los establecimientos de reclusión de Bogotá, Medellín y Cali, así como los de reclusión de mujeres en Jamundí, Popayán y Cúcuta, aglutinan gran parte de esta población. Los problemas que más se han registrado corresponden especialmente a casos en las prisiones de Picaleña (Ibagué), San Cristóbal (Medellín), Jamundí (Valle del Cauca) y El Pedregal (Antioquia). ${ }^{9}$

En este sentido, se determinó que las mujeres lesbianas y bisexuales abarcan la mayor densidad poblacional, seguidas de los hombres gais y de las personas Trans ${ }^{{ }^{*} 10}$.

Los escenarios más problemáticos que aquejan a la población LGBT en centros de reclusión son actuaciones relacionadas con el estado de vulnerabilidad en el que se encuentran estos reclusos por la forma de pensar de los funcionarios de la prisión y de los otros internos, marcados por el prejuicio y los raciocinios homofóbicos y machistas.

Cuando se habla de prejuicio se hace referencia a todas aquellas actitudes, disposiciones, sentimientos y estereotipos realizados sobre un determinado grupo humano, los cuales prevalecen latentes en las personas y pueden orientar ciertas acciones hacia quienes se identifican como parte de esta comunidad ${ }^{11}$. Esta noción de prejuicio demuestra que los casos de discriminación y violencia contra personas lesbianas, gais, bisexuales y Trans ${ }^{*}$, a causa de su orientación sexual o su identidad de género, no son situaciones aisladas. A través de cada uno de estos hechos se busca excluir a las personas o conservarlas en una posición de sometimiento, no como sujetos individuales sino como integrantes de un grupo que socialmente se considera inferior a otros.

Simultáneamente la visibilidad de las sexualidades periféricas en un entorno cerrado como el penitenciario, genera rechazo social, discriminación y estigma, pues sobrepasa la línea de la sexualidad aceptada socialmente: heterosexual, monógama, que rechaza el cambio de sexo y que no permiten admitir a los demás ciudadanos conforme a su identidad sexual ${ }^{12}$. Además, el mal trato que se da a los reclusos debido a su opción sexual, como causa de los criterios sospe-

\footnotetext{
8 Consejo Nacional para prevenir la discriminación (CONAPRED), Discriminación, [en línea], disponible en: http://www.conapred.org.mx/index.php?contenido=pagina\&id=84\&id_opcion=142\&op=14 [consultado el 8 de mayo de 2018]

9 Estadística otorgada por el INPEC en el año 2014.

10 Colombia Diversa, Del amor y otras condenas (2015), Bogotá, pp.16, [en línea], disponible en: http://colombiadiversa.org/colombiadiversa/documentos/informes-dh/colombia-diversa-personas-LGBT-en-carceles-decolombia-2013-2014.pdf [consultado el 8 de mayo de 2018]

${ }^{11}$ GIL, Franklin (2010), Experiencias, reflexiones, y representaciones de "raza" y clase de personas negras de sectores medios en Bogotá .Trabajo de grado para optar por el título de Magister en Antropología, Universidad Nacional de Colombia, Bogotá, p.31, [en línea], disponible en: http://bdigital.unal.edu.co/

${ }^{12}$ Fonseca Hernández, Carlos y Quintero Soto, María Luisa (2009), La teoría Queer: la deconstrucción de las sexualidades periféricas. Revista Sociológica, año 24, número 69, pp. 43-6o.
} 
chosos de discriminación ${ }^{13}$ es contrario al derecho de igualdad, pues las autoridades penitenciarias se enfocan en rasgos esenciales de los reclusos que no pueden cambiar, corriendo el riesgo de afectar su identidad.

\section{Violaciones de derechos humanos}

Las violaciones a los derechos humanos reales o percibidas de las personas de la comunidad LGBT establecen un patrón global y definido que es motivo de grave preocupación, razón por la cual la Corte Constitucional de Colombia aclara que, si bien la privación de la libertad permite que se impongan prohibiciones a algunos derechos fundamentales y restricciones a otros, estas limitaciones deben cumplir con determinadas condiciones, particularmente los requisitos de necesidad, razonabilidad y proporcionalidad. En consecuencia el Tribunal Constitucional estableció:

(i) que las medidas adoptadas no pueden tener un grado de intensidad que implique la afectación del núcleo esencial de derechos diferentes a la libertad de locomoción y la libertad personal; (ii) que la medida tenga como propósito cumplir una finalidad constitucionalmente legítima, esto es, intrínseca y comprobadamente relacionada con los objetivos legítimos de la sanción penal; y (iii) que la medida sea idónea para cumplir el objetivo. Ahora bien, la intensidad del juicio de proporcionalidad dependerá del derecho fundamental que se encuentre en juego. Como se explicará más adelante, cuando la medida adoptada involucre una discriminación entre las personas reclusas fundada un criterio sospechoso, como es la identidad sexual, el juicio deberá ser estricto. En este caso, la medida debe buscar satisfacer un fin constitucional imperioso $y$, a su vez, debe ser imprescindible para lograr tal finalidad ${ }^{14}$.

De acuerdo con el Informe alterno presentado por la Coalición Colombiana Contra la Tortura al cómite contra la tortura de la Organización de las Naciones Unidas (ONU), entre las violaciones más recurrentes contra la población LGBT en los centros de reclusión se encuentran: actos sexuales abusivos; tratos crueles, inhumanos o degradantes; situaciones de violencia física y psicológica; ausencia de medidas por parte de las autoridades penitenciarias para garantizar plenamente sus derechos; normas y prácticas penitenciarias abiertamente contrarias a los derechos de las personas LGBT privadas de la libertad, primordialmente en relación con el debido respeto que merece la identidad Trans ${ }^{\star}$ en los establecimientos carcelarios ${ }^{15}$.

Teniendo en cuenta las violaciones de derechos humanos señalados por la Coalición Colombiana contra la tortura, los casos presentados ante el tribunal constitucional y la Comisión Interamericana de Derechos Humanos, entre otros precedentes, me permito identificar las violaciones a derechos humanos más frecuentes perpetradas contra los reclusos pertenecientes a la comunidad LGBT por parte del personal penitenciario.

\footnotetext{
${ }^{13}$ Las categorías sospechosas aluden a las características propias de una persona que históricamente han estado sujetas a valoraciones potencialmente discriminatorias por ser contrarias a los principios Constitucionales. Confróntese en Corte Constitucional colombiana, sentencia T-314 de 2011, Magistrado Ponente: Jorge Iván Palacio Palacio, [en línea], disponible en: http://www.corteconstitucional.gov.co/relatoria/2011/t-314-11.htm [consultado el 21 de julio de 2018]

${ }^{14}$ Corte Constitucional colombiana. Sentencia T- 062 /11. Magistrado Ponente: Luis Ernesto Vargas Silva, p.1.

${ }^{15}$ Coalición colombiana contra la tortura (2015), Tortura y tratos o penas crueles, inhumanas o degradantes en Colombia. Informe alterno presentado al cómite contra la tortura de la ONU. Bogotá, pp.55-56.
} 


\section{a) Abusos sexuales}

La Corte Constitucional Colombiana estudió diversos casos de vulneraciones sistemáticas de derechos humanos contra homosexuales privados de su libertad, quienes han recibido malos tratos y agresiones sexuales por parte de otros reclusos, agravados por la negligencia ante la falta de atención de las autoridades penitenciarias.

En consecuencia, el Tribunal determinó, con respecto de la reclusión de la población LGBT, que las condiciones de hacinamiento facilitan actos de violencia; al mismo tiempo, los prejuicios respecto a la orientación sexual que gobiernan en los centros de reclusión se convierten en elementos de discriminación hacia homosexuales, aumentando los peligros que desafía esta población. Esta situación de discriminación es usualmente de conocimiento de las autoridades y es muchas veces permitida, pues, conjeturan que el afectado es parcialmente responsable de los abusos a los que ha sido subordinado por su condición de homosexual, conclusión jurídicamente insostenible en un Estado social y democrático de derecho.

Afirma la Corte que la inactividad del Instituto Nacional Penitenciario y Carcelario de Colombia frente a tales injurias establece una grave violación contra los derechos de la vida, integridad física, dignidad humana y libertad sexual de los perjudicados, pues no adopta las herramientas para evitar que otros reclusos abusen sexualmente de sus compañeros y vulneren sus derechos, particularmente si se trata de una persona que integra un grupo que tradicionalmente ha sido discriminado ${ }^{16}$.

\section{b) Muestras de afecto en público sancionadas como faltas disciplinarias}

El prejuicio hacia la orientación sexual o identidad de género llega a proyectarse en violencia cuando ocurren expresiones de afecto, siendo los integrantes de este grupo social expuestos a agresiones físicas, verbales y psicológicas por parte de los démas reclusos y del personal de vigilancia y custodia; estos últimos, imponiendo sanciones disciplinarias que eventualmente pueden obstaculizar el acceso a un programa de rebaja de pena y que posiciona a estos sujetos en una situación de desigualdad ante las oportunidades que tienen los otros reclusos. Adémas, cabe mencionar que sancionar la orientación sexual como falta disciplinaria es contrario a la Constitución Política de Colombia.

\section{c) Impedimentos arbitrarios a la visita íntima de parejas del mismo sexo}

La denegación de las autoridades de consentir el ejercicio del derecho a la visita íntima de los reclusos a causa de su orientación sexual perjudica directamente en la integridad personal e intimidad del solicitante. De hecho, Martha Lucía Álvarez Giraldo interpusó una petición ante la Comisión Interamericana de Derechos Humanos en contra de la República de Colombia por la violación de los derechos mencionados a causa de las mútiples restricciones en la solicitud de visita íntima. A lo que el Estado Colombiano alegó que conceder visitas íntimas a homosexuales perjudicaría el régimen de disciplina interna de los establecimientos carcelarios dado que, en su opinión, la cultura latinoamericana es poco tolerante de las prácticas homosexuales en gene-

\footnotetext{
${ }^{16}$ Corte Constitucional colombiana. Sentencia T-1096 DE 2004. Magistrado Ponente: Manuel José Cepeda Espinosa, [en línea], disponible en: http://www.corteconstitucional.gov.co/relatoria/2004/t-1096-04.htm 
$\mathrm{ral}^{17}$. Argumento inaceptable, pues no puede existir una diferenciación entre la visita íntima de un recluso heterosexual y un recluso homosexual basada en sus preferencias erótico-afectivas. Consecuentemente, la Comisión declaró que las autoridades penitenciarias incurrieron en un trato discriminatorio no acreditado por el derecho interno y violatorio de los artículos 5, 11 y 24 de la Convención Americana sobre Derechos Humanos ${ }^{18}$.

El tribunal Constitucional ha declarado que la permanencia de situaciones contrarias a derechos humanos en el sistema carcelario y penitenciario colombiano son inconstitucionales. Acentúa que las restricciones que se imponen a la población privada de la libertad están limitadas a criterios estrictos de necesidad y proporcionalidad, por tanto no pueden imponerse requisitos a la visita íntima que lleven a conculcar derechos tales como la dignidad humana, la protección de la familia, la intimidad y los derechos sexuales y reproductivos ${ }^{19}$.

\section{d) Represión de la identidad sexual}

En cuanto a los derechos de las mujeres Trans* recluidas en centros de detención, es de suma importancia que estas sean llamadas por su nombre identitario ${ }^{20}$, pues los guardias se empeñan en llamarles por el nombre que les fue asignado al nacer, desconociendo su autonomía individual y libre determinación ${ }^{21}$. De igual forma, la oposición de las autoridades con respecto al ingreso de prendas y accesorios que permitan exteriorizar y vivir según la identidad sexual elegida como propia y el malestar causado a estos reclusos violan el derecho a la libertad de expresión, más exactamente, a la expresión de la identidad o la personalidad mediante el comportamiento, el lenguaje, el atuendo, el aspecto, las características físicas, la elección de nombre, entre otras.

Las necesidades diferenciales de las personas Trans* se intensifican en el ámbito de la salud, dado que las cárceles no cuentan con tratamientos hormonales como parte de su inventario farmacéutico y tampoco ofrecen consultas médicas para dar seguimiento a las dificultades derivadas de procesos de transformación corporal realizados en cirugías clandestinas o como consecuencia de inyecciones de sustancias tóxicas para moldear los cuerpos ${ }^{22}$.

${ }^{17}$ Comisión Interamericana de Derechos Humanos. Informe No 71/99, [en línea], disponible en: https://www.cidh. oas.org/annualrep/99span/Admisible/Colombia11656.htm [consultado el 10 de mayo de 2018]

${ }^{18}$ Convención Americana sobre Derechos Humanos, [en línea], disponible en: https://www.cidh.oas.org/basicos/ spanish/basicos2.htm [consultado el 10 de octubre de 2018]

${ }^{19}$ Corte Constitucional colombiana. Sentencia T-815 de 2013. Magistrada Ponente: Gloria Stella Ortiz Delgado, [en línea], disponible en: http://www.politicacriminal.gov.co/Observatorio/Decisiones-judiciales-LGBTI

${ }^{20}$ Hace referencia a la construcción de la identidad del sujeto, adoptando un nombre que lo identifica, a partir de las características individuales y propias de cada persona, véase en Corte Constitucional colombiana. Sentencia T-815 de 2013. Magistrada Ponente: Gloria Stella Ortiz Delgado, [en línea], disponible en: http://www.politicacriminal.gov.co/Observatorio/Decisiones-judiciales-LGBTI

${ }^{21}$ Colombia Diversa, Caribe Afirmativo y Santa María Fundación (2017), Muchas veces me canso de ser fuerte: ser lesbiana, gay, bisexual o trans en las cárceles de Colombia, 2015-2016, Bogotá, pp. 59-6o.

${ }^{22}$ Las sustancias tóxicas que se utilizan regularmente son el aceite de cocina, aceite industrial, parafina y silicón líquido. La presencia de estos elementos extraños en los cuerpos de las personas puede generar enfermedades agudas de larga duración y hasta mortales, entre ellas se encuentran la hepatitis granulomatosa, embolismo sistemático-masivo, neumonía, paros respiratorios, entre otras, véase en Red Comunitaria Trans (2015), Cartilla para la Defensa de los Derechos de las mujeres Trans y hombres gais privados de la libertad. Bogotá, pp. 16-17. 


\section{e) Manejo improcedente de las unidades de aislamiento}

En la ejecución penitenciaria, el principio de proporcionalidad ${ }^{23}$ se proyecta en la humanidad de la pena de prisión, dependiente del respeto a la dignidad y a los derechos humanos de los reclusos y en contra de los tratos inhumanos o degradantes como las sanciones de aislamiento que permiten el encierro solitario, considerado inhumano por su nivel inaceptable de exclusión ${ }^{24}$.

Mujeres Trans* han sido sometidas al aislamiento extendido en soledad bajo la justificación de su protección, omitiendo que esta medida genera graves consecuencias para su desarrollo emocional y psicológico, además de la obstaculización de una adecuada resocialización y de la violación al principio de proporcionalidad de la pena.

\section{f) Espera injustificada para diagnóstico y tratamiento de enfermedades contagiosas como VIH/SIDA}

Los programas de prevención de enfermedades contagiosas son deficientes o incluso inexistentes. Según un estudio de la Universidad de Antioquia de Colombia, la prevalencia de tuberculosis y otras enfermedades mortales es 20 veces mayor dentro de las cárceles ${ }^{25}$. El acceso de la población privada de libertad a la valoración, tratamiento y atención adecuada y oportuna del VIH representa un objeto de especial preocupación. Como el caso de la acción de tutela T-1096 interpuesta por un interno, quien sostuvo que, debido a su condición de homosexual, otros reclusos lo obligaban a mantener relaciones sexuales con ellos, hasta con personas conocidas por ser portadoras del VIH positivo. Debido a esto, no tenía la certeza de ser paciente VIH positivo. Solicitó el test de Elisa, el cual le fue negado, por lo que tuvo que recurrir ante un juez para que ordenara al INPEC que se tramitará lo pertinente para que se le practicara una prueba del virus del SIDA. Además, el juez fundó la sentencia en la garantía del derecho a la salud y a la vida no únicamente del interno, sino de sus semejantes ${ }^{26}$.

Por su parte, el Estado ha violado los principios y buenas prácticas sobre la protección de las personas privadas de la libertad en las Américas, elaborados por la Comisión Interamericana de Derechos Humanos; de igual manera, los estándares mínimos a satisfacer por los Estados, como el contenido en el derecho de los reclusos a recibir atención médica constante y diligente (regla No. 10) y el derecho de los reclusos a ser examinados por un médico cuando así se requiera $(\text { regla No. } 11)^{27}$.

\section{Obligaciones del estado}

El Estado debe asegurar a las personas privadas de la libertad un trato humano basado en la dignidad, velando por amparar el derecho a la seguridad e integridad personal indistintamente de sus preferencias sexuales o identidad de género. Así pues, el Código Nacional Penitenciario de

\footnotetext{
${ }^{23}$ El principio de proporcionalidad pretende evitar una utilización desmedida de las sanciones que conllevan una restricción de la libertad.

${ }^{24}$ Cervelló Dondreis, Vicenta (2016), Derecho penitenciario $4{ }^{a}$ edición, Tirant lo Blanch, Valencia, p. 34.

${ }^{25}$ De justicia (2016), Mujeres, políticas de drogas y encarcelamiento, Bogotá, p. 33.

${ }^{26}$ Corte Constitucional colombiana. Sentencia T-1096 DE 2004. Magistrado Ponente: Manuel José Cepeda Espinosa, [en línea], disponible en: http://www.corteconstitucional.gov.co/relatoria/2004/t-1096-04.htm

${ }^{27}$ Principios y buenas prácticas sobre la protección de las personas privadas de libertad en las américas de la Comisión Interamericana de Derechos Humanos, [en línea], disponible en: http://www.oas.org/es/cidh/mandato/ Basicos/PrincipiosPPL.asp [consultado el 8 de mayo de 2018]
} 
Colombia garantiza el cumplimiento del derecho a la dignidad humana de las personas privadas de su libertad a través del respeto a las garantías constitucionales y a los derechos humanos universalmente reconocidos, prohibiendo así todo tipo de violencia psíquica, física o moral.

La Corte Constitucional ha afirmado que los derechos a la dignidad humana, el libre desarrollo de la personalidad y la igualdad no son objeto de interrupción o limitación por el hecho de la privación de libertad. En ese sentido y señalando la relación de sujeción en que se encuentran las personas presas frente al Estado, éste tiene la obligación de asegurar a las minorías, diversidad, identidad u opción sexual, con la finalidad de que puedan ejercer a cabalidad los citados derechos fundamentales relativos a las manifestaciones propias de su identidad sexual y que, por esto, no reciban sanciones o malos tratos ${ }^{28}$. Es de importancia resaltar que las sentencias de la Corte Constitucional tienen fuerza vinculante, pues se basan en los principios de confianza legítima, seguridad jurídica e igualdad, señalados en la Constitución Política de Colombia. Por ende, son fuente de derecho para las autoridades y particulares, puesto que son interpretaciones vinculantes de los mandatos de la norma fundante.

La Ley 1709 de 2014, que modifica el Código Penitenciario y Carcelario de Colombia, establece que el Ministerio de Justicia y del Derecho ${ }^{29}$ debe desarrollar un proceso de ajuste de las instituciones que atiendan el funcionamiento de los centros, adecuándolos a la política general carcelaria y a las obligaciones nacionales e internacionales en materia de derechos humanos.

El Estado colombiano suscribió los mencionados principios y buenas prácticas sobre la protección de las personas privadas de libertad en las Américas, donde se considera el valor de la dignidad humana y de los derechos y libertades fundamentales reconocidos por el sistema interamericano y por los demás sistemas de protección internacional de los derechos humanos, consagrando el derecho fundamental que tienen todas las personas privadas de la libertad a ser tratadas humanamente y a que se respete y garantice su dignidad, su vida y su integridad física, psicológica y moral. Del documento en mención, destaca el principio I donde es deber del Estado proteger contra todo tipo de amenazas y actos de tortura, tratos o penas crueles, violencia sexual, castigos corporales, castigos colectivos o tratamiento coercitivo, métodos que tengan como finalidad anular la personalidad o disminuir la capacidad física o mental de la persona. También destaca el principio II por el cual en ninguna circunstancia se discriminará a las personas privadas de libertad por sexo, género, orientación sexual o cualquier otra condición social.

En consecuencia, se prohibirá cualquier distinción, exclusión o restricción que tenga por objeto o por resultado, menoscabar o eliminar el reconocimiento, goce o ejercicio de los derechos internacionalmente reconocidos a las personas privadas de libertad ${ }^{30}$.

$\mathrm{Al}$ analizar el significado normativo implícito del artículo primero de la Convención Americana sobre Derechos Humanos, que fue ratificada por Colombia el 30 de diciembre de $1972^{31}$, se puede inferir que la orientación sexual y la identidad de género de las personas son categorías protegidas, por lo que está prohibida cualquier práctica, actuación o norma discriminatoria encaminada a la sanción de la orientación sexual o identidad de género de la persona. Así,

\footnotetext{
${ }^{28}$ Corte Constitucional colombiana. Sentencia T- 062 /11. Magistrado Ponente: Luis Ernesto Vargas Silva.

${ }^{29}$ Es la entidad encargada de formular, coordinar, ejecutar y evaluar la política pública en asuntos carcelarios y penitenciarios, prevención del delito y respeto de los derechos.

${ }^{30}$ Principios y buenas prácticas sobre la protección de las personas privadas de libertad en las Américas de la Comisión Interamericana de Derechos Humanos, [en línea], disponible en: http://www.oas.org/es/cidh/mandato/ Basicos/PrincipiosPPL.asp [consultado el 8 de mayo de 2018]

${ }^{31}$ Ley 16 de 1972. Por medio de la cual se aprueba la Convención Americana sobre Derechos Humanos "Pacto de San José de Costa Rica". Diario oficial, año CIX. N. 3378o. 5, Febrero, 1973. p.p. 321, [en línea], disponible en: http:// www.acnur.org/fileadmin/Documentos/BDL/2008/6481.pdf [consultado el 10 de octubre de 2018]
} 
ninguna norma, disposición o práctica de derecho interno emitida por autoridades estatales o por particulares, puede restringir o limitar los derechos de un individuo a causa de su opción sexual.

\section{Recomendaciones para el estado colombiano}

La potestad punitiva del Estado se rige por ciertos principios y límites que, en el derecho penitenciario, deben cumplirse en la ejecución de la pena, tal y como sucede con el principio de legalidad que es de suma trascendencia, ya que condiciona al poder de la administración de manera que sus actos estén ajustados a las directrices legales y evite cualquier clase de injusticia por medio de reglamentaciones que se encuentren más allá de lo razonable y lo constitucional.

Sin embargo, la discriminación de la que son víctimas los reclusos pertenecientes a la comunidad LGBT es uno de los principales elementos de vulneración de derechos que, para proteger el goce efectivo de los derechos al libre desarrollo de la personalidad, autonomía individual, intimidad, igualdad y dignidad humana, necesita de la ayuda del Estado en conjunto con la entidad penitenciaria. Además, el Estado tiene que garantizar los principios rectores de la ejecución penitenciaria, como los principios de proporcionalidad, legalidad y reinserción social.

En Colombia se ha establecido la restricción de discriminación debido a la orientación sexual o identidad de género y el deber del Estado, como custodio de los derechos fundamentales, para salvaguardar los principios y expresiones relacionados con diferentes esferas humanas, como las manifestaciones del desarrollo identitario. Es preciso tener en cuenta los informes realizados por las organizaciones no gubernamentales dedicadas a la protección de los derechos de la comunidad LGBT, los principios sobre la aplicación de la legislación internacional de derechos humanos en relación con la orientación sexual y la identidad de género realizados por la Comisión Internacional de Juristas con la colaboración de 29 expertos en el tema ${ }^{32}$, los precedentes judiciales del Tribunal Constitucional y los manuales sobre reclusos con necesidades especiales. Después de su revisión y análisis, se recomienda a las autoridades carcelarias crear políticas y programas que aseguren mayor protección a la comunidad LGBT, evitando la invisibilización de sus problemas y, de esta manera, conceder un trato igualitario a los presidiarios en las siguientes necesidades especiales:

a) Salud

El diagnóstico y el seguimiento de los pacientes portadores del VIH deben estar integrados en los servicios de atención básica de salud prestados en las instituciones de detención. Esto

\footnotetext{
${ }^{32}$ La Comisión Internacional de Juristas junto con un grupo de 29 reconocidas y reconocidos especialistas procedentes de 25 países, de diversas disciplinas y con gran experiencia en el ámbito del derecho internacional de los derechos humanos han redactado, desarrollado, discutido y refinado los Principios de Yogyakarta. Léase "Introducción a los principios de Yogyakarta" en Comisión Internacional de Juristas ICJ (2007), Principios de Yogyakarta: Principios sobre la aplicación de la legislación internacional de derechos humanos en relación con la orientación sexual y la identidad de género, p. 7, [en línea], disponible: http://www.refworld.org.es/ docid/48244egf 2.html [consultado el 1 de abril de 2019]
} 
significa que deben existir servicios médicos de calidad in situ y la disponibilidad de los medicamentos dentro de los centros de reclusión ${ }^{33}$.

El deber del Estado es asegurar a los reclusos integrantes de la comunidad LGBT un adecuado acceso al servicio médico ajustado a sus necesidades en lo que concierne a información sobre el VIH/ SIDA ya que, como se comentó anteriormente, las violaciones en los centros de detención son principalmente ejercidas sobre los presidiarios homosexuales, bisexuales y transexuales, por ejemplo, como cuando los convictos transexuales son situados de acuerdo con su género biológico, en especial los transexuales de hombre a mujer son asignados con hombres ${ }^{34}$; esto da pie a actos sexuales abusivos y violación, con gran riesgo a ser víctimas de delitos sexuales y adquirir esta grave enfermedad.

Usualmente, las necesidades diferenciales de las personas Trans ${ }^{\star}$, con respecto a la reafirmación del género, se ven como una preocupación estetica que no tiene relación con su salud, por lo que a los reclusos con disforia de género ${ }^{35}$, una vez que son arrestados, con frecuencia manifiestan que se les niega el tratamiento médico, como la terapia hormonal ${ }^{36}$. En consecuencia, es necesaria la terapia correspondiente, como también los tratamientos para reasignación sexual si así lo desearan.

Muchos de los integrantes Trans ${ }^{\star}$ de la comunidad LGBT se han realizado algún procedimiento quirúrgico en pro de modificar su apariencia. Usualmente recurren a métodos caseros e inseguros, carentes de los debidos cuidados, que les generan afectaciones en su salud, por lo que es deber de los centros de detención proporcionar una revisión y tratamiento médico a estos pacientes con la intención de preservar su estado de salud en las mejores condiciones posibles e impedir tragedias dentro del reclusorio.

\section{b) Personal penitenciario}

Es de suma importancia que los centros carcelarios implementen programas de adiestramiento y capacitación para su personal relativos al adecuado manejo de los reclusos y con un enfoque de derechos humanos, basado, principalmente, en los principios de no discriminación e igualdad ante la ley, incorporando la perspectiva de orientación sexual e identidad de género. Lo anterior, debido a que una de las vías de mayor preeminencia para la construcción de una sociedad pluralista y respetuosa de los derechos fundamentales es la educación.

Una de las mayores preocupaciones de las personas que viven bajo una medida de aseguramiento es el riesgo que pueden correr frente a un ataque sexual, por esto, deben existir instrucciones y procedimientos claros con respecto a este tipo de abusos. El personal debe tener la disposición de recibir y dar seguimiento a las preocupaciones y quejas interpuestas por las víctimas, velando de esta manera por los derechos a la integridad física y sexual de todos los reclusos.

\footnotetext{
${ }^{33}$ Bockting, Walter y KeAlley, Joanne (2012), Por la salud de las personas trans. Elementos para el desarrollo de la atención integral de las personas trans y sus comunidades en Latinoamérica y el caribe.

34 Comisión Internacional De Juristas (2006), International Human Rights References to Human Rights Violations on the Grounds of Sexual Orientation and Gender Identity, Ginebra, p. 9.

${ }^{35}$ Inconformidad entre el género experienciado y el género asignado.

${ }^{36}$ Comisión Internacional de Juristas (2006), op. cit., p. 9.
} 


\section{c) Visitas intimas}

Hay que certificar que las visitas íntimas se concedan para todos los presos, independientemente del sexo de su pareja, puesto que no deben ser privados de su sexualidad, su intimidad personal y familiar y el libre desarrollo de su personalidad. Los reclusos homosexuales, bisexuales y Trans ${ }^{\star}$ tienen el derecho de vigorizar en la intimidad sus relaciones afectivas sin tener que sufrir ninguna clase de obstáculo para la consecución de la visita conyugal.

\section{d) Distribución y asignación de espacio para los reclusos}

Es de suma importancia velar por la seguridad de los reclusos a través de un entorno que garantice su bienestar. Las personas de la comunidad LGBT nunca deberán ser instaladas en celdas junto con personas que representen un peligro para su integridad. Aunque en 2016 el INPEC expidió el Manual para la correcta aplicación del aislamiento en la Unidad de Tratamiento Especial, el aislamiento continúa aplicándose de forma arbitraria ${ }^{37}$. De hecho, los reclusos Trans ${ }^{*}$ muchas veces son sometidos al aislamiento en soledad para velar por su protección, lo que genera fuertes consecuencias tanto físicas como psicológicas. Es por tal que las autoridades deben adecuar espacios para alojar a estos reclusos y evitar que existan violaciones por parte de sus compañeros de celda y/o por parte del personal penitenciario.

De igual manera, es de importancia evitar que la reclusión en soledad impida a estos reclusos, acceder a programas laborales y educativos que, de no estar en esta condición, estarían disponibles para ellos.

\section{e) Archivo}

Debe existir un método de recopilación de todas las quejas de abusos y vulneraciones a los derechos humanos de los miembros de la comunidad LGBT en razón de su opción sexual o identidad de género. Esto con el objetivo de documentar y determinar todas las situaciones a las que se ven sometidos para evaluar, reportar y realizar un seguimiento de las transgresiones y buscar la mejor manera de solucionarlo, evitando que permanezcan en la impunidad o que se naturalicen esta clase de comportamientos. Además, realizar un archivo histórico para demostrar la evolución y progresividad del cuidado de los reclusos de la comunidad.

\section{f) Servicios especializados para la salud mental}

La salud no abarca únicamente la estabilidad física, si no también el bienestar psicológico y emocional de los individuos, factores que configuran una calidad de vida y un desarrollo integral del ser humano ${ }^{38}$.

Las desmedidas restricciones a derechos humanos que sufren las personas que viven bajo medida de aseguramiento son factores que afectan la salud mental de la población reclusa, ocasionando procesos de despersonalización y desocialización39. La salud mental es una

\footnotetext{
37 Equipo Jurídico pueblos, Informe anual 2017, [en línea], disponible en: https://www.prisoninsider.com/fichapais/prisionesdecolombia\#introduction577e269702da8 [Consultado el 6 de julio de 2018]

${ }^{38}$ Corte Constitucional Colombiana. Sentencia T- 307 /o6. Magistrado Ponente: Humberto Sierra Porto.

39 Oficina de las Naciones Unidas contra la Droga y el Delito UNDOC (2009), Manual sobre Reclusos con necesidades especiales: reclusos homosexuales, bisexuales y transexuales, p. 106.
} 
gran preocupación entre la población LGBT, sobretodo en enfermedades como la ansiedad y la depresión, incluyendo los pensamientos e intentos suicidas ${ }^{40}$ que se asocian con la discriminación y el prejuicio.

Según el informe "Situación de los internos con enfermedad mental sobrevenida en los establecimientos de reclusión del país” de la Defensoría del Pueblo de Colombia, no existe suficiente personal especializado como psiquiatras, trabajadores sociales, enfermeras especializadas, psicólogos y personal de guardia con formación en el trato de estos pacientes para brindar el tratamiento oportuno y adecuado a estos internos ${ }^{41}$.

Teniendo en cuenta lo mencionado, una valoración del estado mental de los integrantes de la comunidad LGBT es primordial, pues este grupo se ve sometido a situaciones psicológicas muy fuertes como, por ejemplo, hacia las personas Trans ${ }^{\star}$ con la no conformidad entre sexo asignado al nacer y su identidad de género, además de los abusos a los que estan sometidos por su condición.

\section{Conclusiones}

La discriminación por orientación sexual o identidad de género en centros de reclusión colombianos representa un gran problema para los reclusos de la comunidad LGBT que se encuentran bajo medida de aseguramiento, pues existen graves violaciones a derechos humanos que no son derivados de la pena privativa de la libertad. Es por tal, y como se ha manifestado a lo largo del texto, que la opción sexual no puede considerarse un parámetro para la imposición de tratamientos de exclusión social, ni diferenciaciones jurídicas o penalidades que limiten los objetivos de los principios constitucionales y los tratados internacionales adoptados por el Estado Colombiano.

La población carcelaria particularmente se aprecia con una actitud problemática, tanto para la sociedad, desde un punto de vista de marginalidad y desprecio, como para el Estado, como una carga excesiva de obligaciones por cumplir. Este último debe garantizar un trato digno, fijando la implementación de métodos para evitar cualquier tipo de violencia en su contra.

Es necesario tener en cuenta que, aunque una persona privada de la libertad no puede ejercer en totalidad de todos sus derechos, el Estado no puede utilizar su condición de presidiario para actuar injustamente, pues la finalidad de la pena tiene que ver con la reintegración social de los reclusos. Sin embargo, en el caso de la comunidad LGBT es más probable que al ingresar a prisión se deteriore su situación. Debido a su fragilidad en los espacios carcelarios, en muchos casos la detención de individuos dentro de los grupos mencionados constituye una condena desmedidamente cruel y coartadora de una adecuada resocialización.

Es deber de las autoridades de los poderes legislativo, ejecutivo y judicial el de respetar, proteger, promover y garantizar los derechos humanos en aplicación a los principios de universalidad, interdependencia, indivisibilidad y progresividad, dado que la prohibición de discriminación motivada por preferencias sexuales que atente contra la dignidad humana y tenga

\footnotetext{
${ }^{40}$ La tasa de suicidios es entre 4 y 10 veces mayor dentro de la prisión, véase en Prision Insider, Integridad física, [en línea], disponible en: https://www.prison-insider.com/fichapais/prisionesdecolombia?s=1-integrite-physique\#lintegrite-physique [consultado el 6 de julio de 2018]

${ }^{41}$ Defensoría del Pueblo (2010), Situación de los internos con enfermedad mental sobrevenida en los establecimientos de reclusión del país, Bogotá.
} 
por objeto menoscabar los derechos y libertades de las personas, se establece con relación a un conjunto de obligaciones especificas respecto al ente estatal.

Es de importancia tener en cuenta que las necesidades de los grupos de reclusos son amplias y las respuestas a ellas pueden cambiar de forma contundente, dependiendo del nivel de desarrollo del sistema de justicia penal, la cultura, las costumbres y la disponibilidad de los recursos. En consecuencia, se realizó un panorama general de las necesidades básicas y las posibles respuestas conforme a los estándares internacionales. Así se pretende forjar un entendimiento más profundo de la situación de los reclusos vulnerables con la intención de promover una nueva forma de pensar y desarrollar estrategias adecuadas que cubran sus requisitos de cuidado y supervisión dentro de las posibilidades y recursos disponibles.

Finalmente, es deber de todos los ciudadanos y de los servidores públicos desprenderse de anatemas, pensamientos cerrados y pretendidamente fehacientes acerca de cómo deben actuar los demás, pues sólo de esta manera estaremos en condiciones para entender que los actos humanos y la particularidad de cada individuo sobrepasan el ideal homogeneizador y reduccionista de las convenciones sociales injustas, reconociendo la diversidad para conseguir una colectividad inclusiva y tolerante, y el compromiso de hacer públicas y populares las necesidades de los individuos en sociedad.

\section{Bibliografía}

\section{Fuentes documentales}

Bockting, Walter y Kealley, Joanne (2012), Por la salud de las personas trans. Elementos para el desarrollo de la atención integral de las personas trans y sus comunidades en Latinoamérica y el caribe.

Cervelló Dondreis, Vicenta (2016), Derecho penitenciario 4ª edición, Valencia, Tirant lo Blanch.

COALICIÓN COLOMBIANA CONTRA LA TORTURA (2015). Tortura y tratos o penas crueles, inhumanas o degradantes en Colombia. Informe alterno presentado al cómite contra la tortura de la ONU, Bogotá.

Colombia Diversa (2015). Del amor y otras condenas, Bogotá, pp.16, [en línea], disponible en: http://colombiadiversa.org/colombiadiversa/documentos/informes-dh/colombiadiversa-personas-LGBT-en-carceles-de-colombia-2013-2014.pdf

Colombia Diversa, Caribe Afirmativo y Santa María Fundación (2017), Entre el miedo y la resistencia. Informe de Derechos humanos de personas lesbianas, gays, bisexuales y trans en Colombia 2017, Bogotá.

Colombia Diversa, Caribe Afirmativo y Santa María Fundación (2017), Muchas veces me canso de ser fuerte: ser lesbiana, gay, bisexual o trans en las cárceles de Colombia, 2015-2016, Bogotá.

Consejo Nacional para prevenir la discriminación (CONAPRED), Discriminación, [en línea], disponible en: http://www.conapred.org.mx/index. php?contenido=pagina\&id=84\&id_opcion $=142 \& o p=14$ 
DefEnsoría DEL PUeblo (2010), Situación de los internos con enfermedad mental sobrevenida en los establecimientos de reclusión del país, Bogotá.

De justicia (2016), Mujeres, políticas de drogas y encarcelamiento, Bogotá.

Equipo JuRídico pueblos (2017), Informe anual 2017, [en línea], disponible en: https://www. prisoninsider.com/fichapais/prisionesdecolombia\#introduction577e269702da8

Fonseca Hernández, Carlos y Quintero Soto, María Luisa (2009), "La teoría Queer: la deconstrucción de las sexualidades periféricas”, Revista Sociológica, año 24, número 69.

GIL, Franklin (2010), Experiencias, reflexiones, y representaciones de "raza" y clase de personas negras de sectores medios en Bogotá .Trabajo de grado para optar por el título de Magister en Antropología, Universidad Nacional de Colombia, p.31, [en línea], disponible en: http://bdigital.unal.edu.co/

Comisión Internacional de Juristas ICJ (2007). Principios de Yogyakarta: Principios sobre la aplicación de la legislación internacional de derechos humanos en relación con la orientación sexual y la identidad de género, [en línea], disponible en: http://www.refworld.org.es/docid/48244egf2.html

Comisión Internacional de JuRistas ICJ (2006). International Human Rights References to Human Rights Violations on the Grounds of Sexual Orientation and Gender Identity, Ginebra.

Oficina de las Naciones Unidas contra la Droga y el Delito UNDOC (2009), Manual sobre Reclusos con necesidades especiales: reclusos homosexuales, bisexuales y transexuales.

Red Comunitaria Trans (2015). Cartilla para la Defensa de los Derechos de las mujeres Trans $y$ hombres gais privados de la libertad, Bogotá.

\section{Jurisprudencia de la corte constitucional colombiana}

Corte Constitucional Colombiana. Sentencia T- 307 /o6. Magistrado Ponente: Humberto Sierra Porto.

Corte Constitucional colombiana. Sentencia T- 499 /o3. Magistrado Ponente: Álvaro Tafur Galvis.

Corte Constitucional colombiana. Sentencia T- 062 /11. Magistrado Ponente: Luis Ernesto Vargas Silva.

Corte Constitucional colombiana. Sentencia T-314 de 2011. Magistrado Ponente: Jorge Iván Palacio Palacio, [en línea], disponible en: http://www.corteconstitucional.gov.co/ relatoria/2011/t-314-11.htm 
Corte Constitucional colombiana. Sentencia T-815 de 2013. Magistrada Ponente: Gloria Stella Ortiz Delgado, [en línea], disponible en: http://www.politicacriminal.gov.co/Observatorio/Decisiones-judiciales-LGBTI

Corte Constitucional colombiana. Sentencia T-1096 DE 2004. Magistrado Ponente: Manuel José Cepeda Espinosa, [en línea], disponible en: http://www.corteconstitucional.gov.co/ relatoria/2004/t-1096-04.htm

Corte Constitucional colombiana. Sentencia T-439 DE 2006. Magistrado Ponente: Marco Gerardo Monroy Cabra, [en línea], disponible en: http://www.corteconstitucional.gov.co/ relatoria/2006/t-439-06.htm

Corte Constitucional colombiana. Sentencia T-099 DE 2015. Magistrada Ponente: Gloria Stella Ortiz Delgado, [en línea], disponible en: http://www.corteconstitucional.gov.co/ RELATORIA/2015/T-099-15.htm

\section{Normatividad nacional e internacional}

Convención Americana sobre Derechos humanos, [en línea], disponible en: https://www.cidh. oas.org/basicos/spanish/basicos2.htm

Comisión Interamericana de Derechos Humanos. Informe No 71/99, [en línea], disponible en: https://www.cidh.oas.org/annualrep/99span/Admisible/Colombia11656.htm

Ley 16 de 1972. Por medio de la cual se aprueba la Convención Americana sobre Derechos Humanos "Pacto de San José de Costa Rica". Diario oficial, año CIX. N. 3378o. 5, Febrero, 1973. p.p. 321, [en línea], disponible en: http://www.acnur.org/fileadmin/Documentos/ BDL/2008/6481.pdf

Principios y buenas prácticas sobre la protección de las personas privadas de libertad en las Américas de la Comisión Interamericana de Derechos Humanos, [en línea], disponible en: http://www.oas.org/es/cidh/mandato/Basicos/PrincipiosPPL.asp 